\title{
Equine Infectious Anemia
}

National Cancer Institute

\section{Source}

National Cancer Institute. Equine Infectious Anemia. NCI Thesaurus. Code C84694.

A horse disease caused by a retrovirus which is transmitted by biting flies. The acute phase symptoms include high fever, anemia, weakness, and swelling of the legs. The subacute phase symptoms include splenomegaly, anemia, and weight loss. The chronic phase symptoms include recurrent fevers and anemia. 